\title{
METODE PENGEMBANGAN PEMBELAJARAN BAHASA DALAM PENGUATAN TUJUAN PENDIDIKAN ANAK USIA DINI (PAUD)
}

\author{
Sukrin, HT \& Abdussahid ${ }^{1}$ \\ Pengajar pada Institut Agama Islam Muhammadiyah Bima \\ gmail:babaraoht69@gmail.com
}

\section{ABSTRAK}

Metode Pengembangan Pembelajaran Bahasa Dalam Penguatan Tujuan Pendidikan Anak Usia Dini (PAUD) yakni: menggunakan metode dan tekhnis yang terukur dalam pembelajaran dan pengajaran Pendidikan Anak Usia Dini yang perlu diterapkan dalam proses pengembangan bahasa adalah:

1) Metode pengembangan Pembelajaran Bahasa di Pendidikan Anak Usia Dini (PAUD), dengan metode: (1) Metode Berdialog atau bercakap-cakap, (2) Metode Bercerita, (3) Metode Tanya Jawab, Sedangkan 2) Penguatan Pengajaran Pendidikan Anak Usia Dini (PAUD), yakni: "bermain sambil belajar", sedangkan untuk memacu kecerdasan bahasan (linguistik) pada pendidikan anak usia dini: (1) kecerdasan kebahasaan merupakan kecerdasan yang paling universal. Ada dua tipe perkembangan kebahasaan (berbicara) yaitu (1) egosentric speech terjadi ketika anak berusia 2 sampai 3 tahun, karena anak mulai berbicara pada dirinya sendiri, (2) Socialized speech ketika anak berinteraksi dengan teman atau lingkungannya mngembangkan adaptasi sosial anak yakni saling bertanya, bertukar informasi.

Kata Kunci: Metode Pengembangan Bahasa, dan Penguatan Tujuan Pendidikan Anak Usia Dini (PAUD)

\section{PENDAHULUAN}

Bahasa dalam kehidupan manusia sangat penting, baik sebagai makhluk individu maupun sebagai makhluk sosial. Tampa bahasa

\footnotetext{
${ }^{1}$ Sukrin, HT \& Abussahid, Merupakan Pengajar pada Institut Agama Islam Muhammadiyah Bima
}

Jurnal Pelang̉i Jurnal pemikiran dan penelitian pendidkan Islam anak Usia Dini 
kehidupan manusia akan hampa dan sunyi. Bahasa yang mewujudkan manusia yang berbudi dan bahasa pulalah yang membedakan manusia dengan makhluk lain dimuka bumi ini.

Dalam tataran bahasa sebagai pembedah manusia dengan mahkluk lain, maka manusia dapat memanfaatkan bahasa berfungsi sebagai a). Bahasa sebagai alat komunikasi; Dengan menggunakan bahasa, manusia dapat berhubungan dengan alam sekitarnya terutama sesama manusia, menyampaikan kehendaknya, merumuskan apa yang dipikirkan, sakit, dan lain-lain, b). Bahasa sebagai alat untuk ekspresi diri; manusia menyatakan secara terbuka segala sesuatu yang tersurat dalam pikirannya kepada orang lain. Bayi yang menangis merupakan ekspresi diri pertanda haus, lapar, sakit, dan lan-lain, c). Bahasa sebagai alat menampung kebudayaan; d).bahasa sebagais Alat mengadakan control social,semua kegiatan sosial akan berjalan dengan baik karena dapat diatur dengan menggunakan bahasa,dapat mempengaruhi tingkah laku dan tindak tanduk orang lain baik terbuka maupun tertutup. ${ }^{2}$ Dari gambaran pemakaian dan pemanfaatan bahasa untuk berbagai aktivitas kehidupan manusia maka ada beberapa pandangan para ahli tentang bahasa. Bahasa adalah ucapan pikiran perasaan manusia yang keluar melalui rongga mulut.

Menurut Ensiklopedia Indonesia bahasa adalah perkumpulan kata dan aturan yang tetap di dalam menggabungkannya berupa kalimat, merupakan sistem bunyi yang melambangkan pengertian-pengertian tertentu. ${ }^{3}$ Sedangkan Menurut Yus Badudu, bahasa merupakan alat penghubung atau komunikasi antaranggota masyarakat yang terdiri dari individu-individu yang menyatakan perasaan, dan keinginannya. ${ }^{4}$

Jika kita menganalisis apa yang meenjadi pandangan para pakar kebahasaan di atas, anak usia dini adalah salah satu komponen masyarakat yang unik yang terdiri dari induvidu untuk dapat dibimbing dan ajarkan tentang bahasa yang baik dan benar sebagai titik awal dalam mengenal titik selanjutnya yang disebutkan dengan ranah kognitif,afektif dan konatif(penghayatan) dengan teknis dan metode yang terukur.

Metode dalam pembelajaran menjadi sangat penting. Metode

${ }^{2}$ Nursalim A.R. Pengantar Kemampuan Berbaahasa Indonesia Berbasis Kompetensi, Yogyakarta, Nusa Media, 2011. 2

${ }^{3}$ Ensiklopedia Indonesia. Kamus Besar Bahasa Indonesia, Jakarta, Perum Balai Pustaka, 1980

${ }^{4}$ Yus Badudu. Pelik-pelik Bahasa Indonesia, Bandung, Pustaka Prima, 1989 
menjadi cara atau strategi untuk menyampaikan pesan kepada Anak Usia Dini agar tersampaiakan dengan baik dan benar. Metode Pengembangan Pembelajaran Bahasa DalamPenguatan TujuanPendidikan AnakUsiaDini (PAUD) yakni bahasa reseptif yang terlebih dahulu harusdikembangkan sebelum mengembangkan kemampuan bicara yang merupakan salah satu media untuk menyampaikan pesa dalam wujud bahasa lisan atau bahasa ekspresif. ${ }^{5}$ Pada mulanya, bahasa anak-anak bersifat egosentris, yaitu bentuk bahasa yang lebih menonjol diri sendiri, berkisar pada minat, keluarga, dan miliknya sendiri. Menjelang akhir masa anak-anak awal percakapan anak-anak berangsur-angsur berkembang menjadi bahasa sosial. ${ }^{6}$ Piaget menjelaskan, perkembangan bahasa secara keseluruhan sebagai hasil interaksi anak dengan lingkungan dan juga kemampuan kognitif dan pengalaman bahasa. ${ }^{7}$ Vygotsky menjelaskan, pembelajaran bahasa terjadi melalui interaksi sehari-hari dan berbagai pengalaman antara orang dewasa dan anak-anak. ${ }^{8}$

\section{METODE PENGEMBANGAN PEMBELAJARAN BAHASA DI PENDIDIKAN ANAK USIA DINI (PAUD)}

Metode dan teknis yang terukur dalam pembelajaran dan pengajaran pendidikan anak Usia Dini yang perlu diterapkan dalam proses pengembangan pembelajaran bahasa adalah:

\section{Metode Berdialog atau Bercakap-cakap}

Metode bercakap-cakap merupakan suatu penyampaian pengembangan bahasa yang dilaksanakan melalui bercakap-cakap antara guru dengan anak. Seorang guru harus mampu mencari tema yang menarik untuk dibahas bersama dengan anak. Metode ini digunakan untuk melatih keberanian anak dalam menyampaikan pendapat kepada siapapun. Menurut Moeslihatun metode bercakap-cakap ini bertujuan

\footnotetext{
${ }^{5}$ Henawati, Tati. Pengembangan Kemampuan Berbahasa dan Berbicara Anak Tunarungu: "Jurnal JASSI_anakku7.1.(2007): 101

${ }^{6}$ Desmita. Psikologi Perkembangan. Bandung: Remaja Rosdakarya, 2013. 140

${ }^{7}$ Mehdi Dastpak, et.al. "A Comparative Study of Vygotsky Perspectives on Child Language Development with Nativism and Behaviorism". International Journal of Languages' Education and Teaching 5.2. 2017. 232

${ }^{8}$ Randima Rajapaksha. Promoting Oral Language Skill In Preschool Children Through Socio dramatic Play in the Classroom International Jounal of Education 4.1. 2016. 17
}

Jurnal Pelang̉i Jurnal pemikiran dan penelitian pendidkan Islam anak Usia Dini 
untuk memberi kesempatan kepada anak untuk berekspresi secara lisan serta mengembangkan intelegensi anak dan menambah perbendaharaan kosa kata. ${ }^{9}$ Sedangkan menurut Gordon bercakap-cakap dapat diartikan sebagai dialog atau berbagai perwujudan bahasa reseptif dan ekspresif dalam suatu situasi. ${ }^{5}$ Widodo berpendapat bahwa ekspresif adalah kemampuan anak untuk mengeluarkan kata-kata yang berarti. ${ }^{10}$ Fizal berpendapat pula bahwa bahasa ekspresif adalah bahasa lisan dimana mimik, intonasi, dan gerakan tubuh dapat bercampur menjadi satu untuk mendukung berkominikasi,

Dalam mewujudkan komunikasi dan ekspresi dialog dengan menggunakan mimik dan intonasi bahasa secara baik maka perlu secara teknik guru mengajarkan bahasa dengan bentuk metode bercakapcakap antara lain; Bercakap-cakap bebas, bercakap-cakap menurut pokok bahasan dan bercakap-cakap dengan menggunakan gambar seri, derngan demikian guru dapat memgajarkan bahasa pada anak yang mengandung kosa kata secara sederhana yang tidak bermakna ambiugitas atau seorang guru dapat mengajarkan kepada anak usia dini dengan kata yang bermakna lugas (denotative) yaitu mengandung makna sebenarnya tanpa membebani sekat psikologis artinya seorang guru dapat mengajarkan pengembangan bahasa dengan berdiolog, berkomunikasi dengan metode bercakap-cakap, sebagai langkah awal guru mengajarkan kebahasaan.

Dengan bercakap-cakap ini pula guru dapat memahami secara langsung kefasihan dan kemampuan kebehasaan pada anak, sehingga guru dapat membantu meluruskan pengucapan kosa kata yang dituturkan oleh anak yang secara tidak jelas menjadi wajar dan jelas melalui ujaran secara terbatas baik bercakap bebas maupun bercakap yang telah dipersiapkan oleh guru dengan pokok bahasan atau tema.

\section{Metode Bercerita}

Dalam pengembangan pembelajaran bahasa pada pendidikan anak usia dini maka, seorang guru perlu pula menjadikan metode bercerita sebagai salah satu pemberian pengalaman belajar bagi anak Usia Dini dengan membawakan cerita kepada anak secara lisan, maka

${ }^{9}$ Gordon. Penerapan Metode Bercerita. Makalah IAIM Bima, 2017, 10

${ }^{10}$ Widodo. Perkembangan Bicara dan Bahasa: Perkembangan Bahasa Prasekolah, 2008, 4 
akan memberikan rangsangan imajinatif kebahasaan kepada anak dengan catatan cerita yang dibawakan oleh guru harus menarik dan mengundang perhatian anak. Penggunaan cerita sebagai salah satu strategi pembelajaran untuk anak Usia Dini dapat pula mengembangkan dan melatih kemampuan bahasa yang anak miliki dan dengan melalui cerita anak lebih dituntut aktif dalam mengembangkan bahasanya khususnya bahasa ekspresif (kosa kata yang keluar secara spontanitas bawaan) dan dapat dibantu oleh arahan dan bimbingan guru. Metode bercerita adalah metode yang sangat menarik karena sangat disenangi oleh anak-anak apalagi disertai dengan penggunaan kata yang sederhana dan mudah dipahami oleh anak-anak sehingga anak lebih berpotensi dalam mengembangkan bahasa yang ekspresif (bersifat bawaan), sebagaimana pandangan Bachri bahwa cerita adalah menuturkan sesuatu yang mengisahkan tentang perbuatan atau kejadian untuk disampaikan secara lisan dengan tujuan membagikan pengalaman dan pengetahuan kepada orang lain atau upaya untuk mengembangkan potensi kemampuan berbahasa. ${ }^{11}$

Dengan demikian metode bercerita adalah cara penyampaian atau pemaparan materi pembelajaran secara lisandalam bentukcerita oleh guru kepada peserta didik dan dilaksanakan dalam upaya memperkenalkan keterangan atau penjelasan tentang hal baru kebahasaan yang bermakna lugas dalam mengembangkan berbagai potensi dasar anak Usia Dini. Oleh karena demikian materi cerita yang disampaikan harus memiliki kesatuan yang utuh.

Juga isi cerita harus terkait dengan dunia kehidupan anak, sehingga anak memahami isi cerita tersebut, kegiatan bercerita diusahakan dapat memberikan perasaan gembira, lucu dan mengasyikan sesuai dengan kehidupan anak yang penuh suka cita, serta kegiatan bercerita diusahakan menjadi pengalaman yang bersifat unik dan menarik bagi anak.

Untuk dapat bercerita dengan baik, pendidik pada saat melaksanakan proses pengajaran bahasa dengan metode cerita harus menyiapkan beberapa hal yang diperlukan mulai dari memilih jenis cerita, menyiapkan tempat, menyiapkan alat peraga, meguasai isi cerita secara tuntas, memiliki keterampilan bercerita, melatih dalam irama dan

${ }^{11}$ Bachri.Perkembangan Kegiatan Bercerita Tekhnik dan Prosedurnya, Jakarta, 2005, 10

Jurnal Pelangi Jurnal pemikiran dan penelitian pendidkan Islam anak Usia Dini 
modulasi suara secara terus-menerus. Seorang guru untuk menuntaskan pengajaran bahasa kepada pendidikan anak Usia Dini perlu melakukan penguatan dengan teknik-teknik membaca langsung dari buku cerita, bercerita dengan menggunakan ilustrasi, menceritakan dongeng, dramatisasi suatu cerita, bercerita sambil memainkan jari-jari tangan. ${ }^{12}$

\section{Metode Tanya Jawab}

Pengembangan kebahasaan pada pendidikan anak Uisa Dini mulamula dengan cara bertanya sambil menunjukkan berbagai benda-benda yang dilihatnya (meja,kursi,bunga dll) atau kata yang dapat menunjukkan pada pengertian tempat, seperti " Di sini " atau "Sekarang"

Metode tanya jawab biasanya dapat digunakan dengan metode lain yang disebut metode bantu. Menurut Departemen Pendidikan dan Kebudayaan (Depdikbud), adalah suatu metode dalam pengembangan bahasa yang dapat memberi rangsangan agar anak aktif untuk berfikir, melalui pertanyaan-pertanyaan guru, anak akan berusaha memahaminya dan menemukan jawabannya. ${ }^{13}$ Metode tanya jawab ini merupakan bentuk penguatan terhadap pemahaman dan karakter mental dan tanggungjawab kejujuran pada anak, sehingga guru dapat mengidentifikasi kemampuan kebahasaan pada seorang anak didik.

\section{PENGUATAN PENGAJARAN PENDIDIKAN ANAK USIA DINI (PAUD)}

Sebaik apapun kurikulum dan metode yang diterapkan kepada pendidikan anak usia dini, tidak akan memberikan hal yang maksimal apabila guru tidak secara kontinyu melakukan penguatan dengan disertai hati dan kesabaran sebab dunia anak Pendidikan Anak Usia Dini (PAUD) itu unik, prinsip belajarnya adalah "bermain sambil belajar" Karena, memacu kecerdasan kebahasaan (linguistik) pada pendidikan anak Usia Dini merupakan kegiatan yang sangat penting, diantara komponen kecerdasan yang lain, kecerdasan kebahasaanlah merupakan kecerdasan yang paling universal. Hal ini sesuai dengan pandangan Nurbiana yaitu

\footnotetext{
${ }^{12}$ Tampubolon. Mengembangkan Minat dan Kebiasaan Membaca Pada Anak. Bandung Angkasa, 1991, 18.

${ }^{13}$ Depdikbud. Team Penyusun Pedoman Pembelajaran Bidang Pengembangan Berbahasa di Taman Kanak-Kanak, Jakarta, 1998.
} 
ada dua tipe perkembangan kebahasaan (berbicara) yaitu pertama egosentric speech terjadi ketika anak berusia 2 sampai 3 tahun dimana anak mulai berbicara pada dirinya sendiri, kedua socialized speech ketika anak berinteraksi dengan teman atau lingkungannya, mengembangkan adaptasi sosial anak yaitu saling bertanya, tukar informasi. ${ }^{14}$

Perkembangan kemampuan bahasa pada anak taman kanak-kanak atau PAUD adalah perubahan yang terjadi yang ditandai dengan perkembangan bahasa anak sebagaimana pandangan Mustakim Nur bahwa perkembangan bahasa yang dimaksud adalah perkembangan bunyi, perkembangan kata, perkembangan kalimat, dan perkembangan makna : pertama, perkembangan bunyi (fonologi) bunyi yang dihasilkan organ artikulasi mengalami perubahan dan penyempurnaan dalam mengucapkan bunyi konsonan/vokal kemudian berkembang menjadi fonem seperti fonem "Str" pada kata "Strika", kedua perkembangan kata morfologi pada anak dari satu kata menjadi kata, dua kata menjadi kalimat misalnya "Mama Alan mencubit saya", ketiga perkembangan kalimat (sintaksis) anak menyusun kalimat dari kata yang diketahui dan dikenalnya, perkembangan kalimat pada anak diperoleh dari lingkungan keluarga. Anak mulai menyusun kalimat pertama mulai dari kata benda (subyek) kemudian kata kerja (predikat) misalnya "Kakak makan nasi", empat perkembangan makna (semantik) perkembangan semantik pada anak sudah nampak sejak anak itu menggunakan kalimat yang terdiri dari dua kata. ${ }^{15}$

Penguatan pengembangan pengajaran kebahasaan pada anak Usia Dini melalui metode, berdialog (bercakap-cakap), bercerita, dan Tanya jawab,seorang guru pada saat proses pembelajaran menyampaikan dengan penggunaan kata-kata yang bersifat reward yaitu kata pujian,dan menghindari kata-kata yang bersifat punishment atau hukuman, sehinggas ending (akhirnya) akan menghasilkan harapan pengembangan kebahasaan kepada anak berupa (1) pemahaman mengucapkan bunyi konsonan dan vokal kemudian berkembang menjadi fonem (2) pemahaman kata pada anak dari satu kata menjadi dua kata menjadi klausa dan kalimat (3)pemahaman kalimat dari kata yang diketahuinya

\footnotetext{
${ }^{14}$ Nurbiana. Metode Pengembangan Bahasa, (Jakarta, Universitas Terbuka, 2006, 7

${ }^{15}$ Mustakimnur, dkk. Metode Pengembangan Bahasa, Jakarta, Universitas Terbuka, 2001, 24
}

Jurnal Pelangi Jurnal pemikiran dan penelitian pendidkan Islam anak Usia Dini 
(4) pemahaman semantik atau makna.

Dan pada hakikatnya penguatan pengajaran kebahasaan sebagaimana harapan dalam penggunaan metode di atas adalah suatu kristalisasi tujuan Pendidikan Anak Usia Dini (PAUD )untuk memfasilitasi pertumbuhan dan perkembangan anak secara menyeluruh atau menekankan pada pengembangan seluruh aspek kepribadian anak. Oleh karena itu, Pendidikan Anak Usia Dini (PAUD) memberikan kesempatan bagi anak untuk mengembangkan kepribadian dan potensi secara maksimal. Atas dasar ini PAUD perlu menyediakan berbagai kegiatan yang dapat mengembangkan berbagai aspek perkembangan seperti, kognitif, bahasa, sosial, emosi, fisik, dan motorik. ${ }^{16}$

\section{KESIMPULAN}

Metode Pengembangan Pembelajaran Bahasa Dalam Penguatan Tujuan Pendidikan Anak Usia Dini (PAUD) yakni: menggunakan metode dan tekhnis yang terukur dalam pembelajaran dan pengajaran Pendidikan Anak Usia Dini yang perlu diterapkan dalam proses pengembangan bahasa adalah:

1) Metode pengembangan Pembelajaran Bahasa di Pendidikan Anak Usia Dini (PAUD), dengan metode: (1) Metode Berdialog atau bercakap-cakap, (2) Metode Bercerita, (3) Metode Tanya Jawab, Sedangkan

2) Penguatan Pengajaran Pendidikan Anak Usia Dini (PAUD), yakni: "bermain sambil belajar", sedangkan untuk memacu kecerdasan bahasan (linguistik) pada pendidikan anak usia dini: (1) Kecerdasan kebahasaan merupakan kecerdasan yang paling universal. Ada dua tipe perkembangan kebahasaan (berbicara) yaitu (1) egosentric speech terjadi ketika anak berusia 2 sampai 3 tahun, karena anak mulai berbicara pada dirinya sendiri, (2) Socialized speech ketika anak berinteraksi dengan teman atau lingkungannya mngembangkan adaptasi sosial anak yakni saling bertanya, bertukar informasi.

\footnotetext{
${ }^{16}$ Suyadi. Teori Pembelajaran Anak-Anak Usia Dini Dalam Kajian Neurosains, Bandung: PT Remaja Rosdakarya, 2014, 22
} 


\section{REFERENSI}

Bachri. Perkembangan Kegiatan Bercerita Tekhnik dan Prosedurnya, Jakarta, 2005.

Depdikbud. Team Penyusun Pedoman Pembelajaran Bidang Pengembangan Berbahasa di Taman Kanak-Kanak, Jakarta, 1998.

Desmita. Psikologi Perkembangan. Bandung: Remaja Rosdakarya, 2013.

Ensiklopedia Indonesia. Kamus Besar Bahasa Indonesia, Jakarta, Perum Balai Pustaka, 1980.

Gordon. Penerapan Metode Bercerita. Makalah IAIM Bima, 2017

Henawati, Tati. Pengembangan Kemampuan Berbahasa dan Berbicara Anak Tunarungu: “Jurnal JASSI_anakku7.1. (2007).

Mustakimnur, dkk. Metode Pengembangan Bahasa, Jakarta, Universitas Terbuka, 2001.

Mehdi Dastpak, et.al. "A Comparative Study of Vygotsky Perspectives on Child Language Development with Nativism and Behaviorism". International Journal of Languages' Education and Teaching 5.2. 2017.

Nursalim A.R. Pengantar Kemampuan Berbaahasa Indonesia Berbasis Kompetensi, Yogyakarta, Nusa Media, 2011.

Nurbiana. Metode Pengembangan Bahasa, (Jakarta, Universitas Terbuka, 2006.

Randima Rajapaksha. Promoting Oral Language Skill In Preschool Children Through Socio dramatic Play in the Classroom International Jounal of Education 4.1. 2016. 17.

Suyadi. Teori Pembelajaran Anak-Anak Usia Dini Dalam Kajian Neurosains, Bandung: PT Remaja Rosdakarya, 2014.

Tampubolon. Mengembangkan Minat dan Kebiasaan Membaca Pada Anak. Bandung Angkasa, 1991.

Widodo. Perkembangan Bicara dan Bahasa: Perkembangan Bahasa Prasekolah, 2008.

Yus Badudu. Pelik-pelik Bahasa Indonesia, Bandung, Pustaka Prima, 1989. 